Southern Illinois University Edwardsville SPARK

SIUE Faculty Research, Scholarship, and Creative Activity

$7-1-2015$

\title{
Fabrication and Material Characterization of Copper and Copper-CNT Micropillars
}

\author{
Siavash Ghanbari \\ sghanba@siue.edu \\ Jeff Darabi \\ jdarabi@siue.edu
}

Follow this and additional works at: http://spark.siue.edu/siue_fac

Part of the Nanoscience and Nanotechnology Commons

\section{Recommended Citation}

Ghanbari, Siavash and Darabi, Jeff, "Fabrication and Material Characterization of Copper and Copper-CNT Micropillars" (2015). SIUE Faculty Research, Scholarship, and Creative Activity. 4.

http://spark.siue.edu/siue_fac/4

This Article is brought to you for free and open access by SPARK. It has been accepted for inclusion in SIUE Faculty Research, Scholarship, and Creative Activity by an authorized administrator of SPARK. For more information, please contact gpark@siue.edu. 


\section{Cover Page Footnote}

This is an author-created, un-copyedited version of an article published in Materials Research Express by IOP Publishing Ltd. The Version of Record is available online at http:/ /dx.doi.org/10.1088/2053-1591/2/7/ 075501. 


\title{
Fabrication and Material Characterization of Copper and Copper-CNT Micropillars
}

\author{
S. Ghanbari and J. Darabi* \\ Department of mechanical engineering \\ Southern Illinois University Edwardsville \\ Edwardsville, Illinois, 62026, USA
}

*Author to whom correspondence should be addressed:

Phone: (618) 650-3382, email: jdarabi@ siue.edu

\begin{abstract}
In this work, copper micropillars and copper-carbon nanotube (CNT) composite micropillars were fabricated by incorporating an electrodeposition technique with a xurography process. In order to disperse carbon nanotubes in copper-CNT micropillars, various amounts of CNTs were added to the electroplating bath. Surface morphology and phase characterization of copper micropillars and copper-CNT composite micropillars were analyzed by optical microscopy and X-ray diffraction. In addition, the corrosion resistance $\left(R_{p}\right)$ of a bare copper substrate, copper micropillars, and optimum copper-CNT micropillars were studied by electrochemical impedance spectroscopy (EIS) technique in a 3.5 wt. \% sodium chloride. Experimental results yielded a corrosion resistance of $200 \Omega \mathrm{cm}^{2}$ for the bare copper substrate, $400 \Omega \mathrm{cm}^{2}$ for copper micropillars, and $2550 \Omega \mathrm{cm}^{2}$ for copper-CNT micropillars, indicating a significantly higher corrosion resistance for copper-CNT micropillars due to a lower chemical reactivity and refinement of crystal structure of copper in micropillars.
\end{abstract}

Keywords: Electrodeposition, Micropillars, carbon nanotubes, Corrosion, Electrochemical impedance spectroscopy (EIS), electronics cooling.

\section{Introduction}

The production of composite coatings by electroplating of semi conductive $[1,2]$ and conductive [3] particles has been used considerably in many industries. In recent years, various $\mathrm{Ni}$ and $\mathrm{Cu}-$ based composite coatings that include micro-/nano-sized particles have been investigated by the 
This is an author-created, un-copyedited version of an article published in Materials Research Express. IOP Publishing Ltd is not responsible for any errors or omissions in this version of the manuscript or any version derived from it. The Version of Record is available online at doi:10.1088/2053-1591/2/7/075501.

electrodeposition technique such as $\mathrm{Ni}-\mathrm{Al}_{2} \mathrm{O}_{3}[4,5]$, Ni graphite [6], Ni-WC [7, 8], Ni-SiC [9, 10], $\mathrm{Ni}_{-} \mathrm{SiO}_{2}$ [11], Ni-BN [12] and Ni-CNT [13]. It has been suggested that co-deposition of particles on a metallic substrate is caused by the adsorption of metal ions on the surface [14]. Several studies have focused on controlling electroplating parameters such as particle concentration, bath composition, current density, temperature, time, and organic additives to increase physical and mechanical properties of composite coatings, and to improve their anticorrosion behavior and wear resistance $[15,16]$. Many theories have been suggested, including co-deposition of inert particles into the metal matrix due to electrophoresis. The adsorption mechanism of metal ions and particles had been adopted by several authors [5, 12]. The codeposition mechanism can be described by the following five-step process[14, 17]: (1) formation of ionic clouds on the particles, (2) convection towards the cathode, (3) diffusion through a hydrodynamic boundary layer, (4) diffusion through a concentration boundary layer, and (5) adsorption at the cathode, where particles are entrapped within the metal deposit.

Copper has a good thermal conductivity and has been the material of choice for applications that require a high thermal conductivity such as electronics cooling. However, mechanical and chemical properties of pure copper may not be suitable for some of these applications. A second phase can be added to copper to improve the mechanical properties of the composite material but it worsens its thermal and electrical properties. It has been reported that CNT particles can improve mechanical properties and anticorrosion behavior of copper without affecting other physical properties [18-21]. In addition, copper-CNT composite coatings are more resistant to corrosion than single phase electroplated coatings such as Ni-CNT [22]. Copper-CNT composite coatings can be produced using electroplating technique. This method is simple, affordable, and can be easily integrated with microelectromechanical systems [23]. Dispersion of CNT particles in composite coatings is a crucial requirement to obtain uniform properties [24]. One approach to disperse CNT particles in a solution is to use the activation method in which CNT particles are surrounded by a surfactant such as sodium dodecyl sulfate (SDS), giving them a negative charge $[25,26]$. Copper-CNT micropillars hold a great promise for many engineering applications including capillary-driven two-phase cooling systems such as passive heat pipes and vapor chambers. Innovative cooling techniques are needed for effective cooling of future high power 
This is an author-created, un-copyedited version of an article published in Materials Research Express. IOP Publishing Ltd is not responsible for any errors or omissions in this version of the manuscript or any version derived from it. The Version of Record is available online at doi:10.1088/2053-1591/2/7/075501.

electronic devices and systems [27]. Passive heat pipes and vapor chambers are suitable for applications where conventional air cooling solutions are not sufficient [28].

In this paper, we report an innovative method by combining an electrochemical deposition method and a Xurography technique to fabricate copper and copper-CNT micropillars on conductive substrates for effective cooling of high power electronic components and systems. The effects of electroplating parameters on the deposition of CNT particles were investigated. In addition, the corrosion behavior of copper and copper-CNT micropillars were studied using EIS techniques and compared with a bare copper substrate. Furthermore, surface structures of the micropillars and phase characterization were characterized by optical microscopy $(\mathrm{OM})$ and Xray diffraction (XRD) analysis, respectively. This work is ongoing and our future research will be focused on the thermal characterization of the fabricated micropillars.

\section{Experimental}

Square specimens, $26 \mathrm{~mm}$ on each side and $0.6 \mathrm{~mm}$ thick were made from copper alloy 110. Specimens were abraded using $800 \mathrm{SiC}$ water proof papers and cleaned with acetone. A process flow for fabrication of micropillars is shown in Fig. 2. A Xurography technique was used to make the pattern for micropillar arrays. Xurography is a simple and inexpensive process that uses a cutting plotter to cut a template design on a polymer sheet [29]. The pattern is transferred and pressed to a substrate and unwanted parts of the sheet are removed. The micropillar pattern was designed in AutoCAD software and cut on a double-sided polyimide tape using a CraftRobo plotter (Graphtec USA, Santa Ana, CA). This method was found to be rapid, inexpensive, and simple for making micropillar array templates. The micropilllar pattern was $500 \mu \mathrm{m}$ in diameter and $365 \mu \mathrm{m}$ apart. The overall dimensions of micropilllar array were $14 \mathrm{~mm}$ by $14 \mathrm{~mm}$ and 200 $\mu \mathrm{m}$ tall. The thickness of the double sided polyimide tape was $100 \mu \mathrm{m}$. To obtain $200 \mu \mathrm{m}$ tall micropillars, two layers of the double sided polyimide tape were attached together. After cutting the micropilllar pattern, the polyimide tape was transferred and attached to the polished side of the copper specimens and the excess materials were removed under a microscope using tweezers to define the micropillar pattern (Figs. 2 a \& 2b). The backside of the specimen was coated with a polymer Nitrocellulose to prevent electrical conduction during electroplating. 


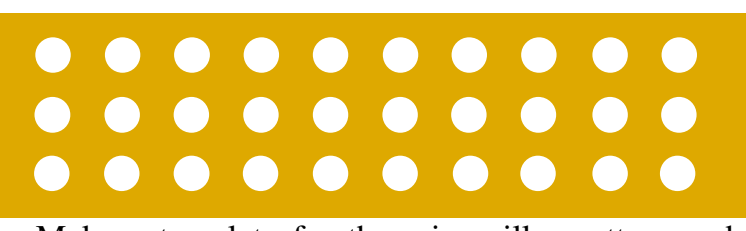

a. Make a template for the micropillar pattern and cut into a double-sided polyimide tape (top view)

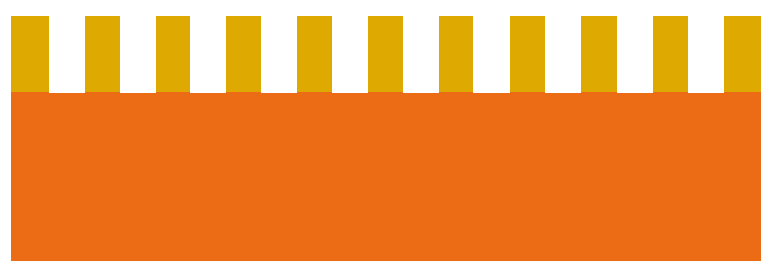

b. Attach the micropilllar template to a copper substrate
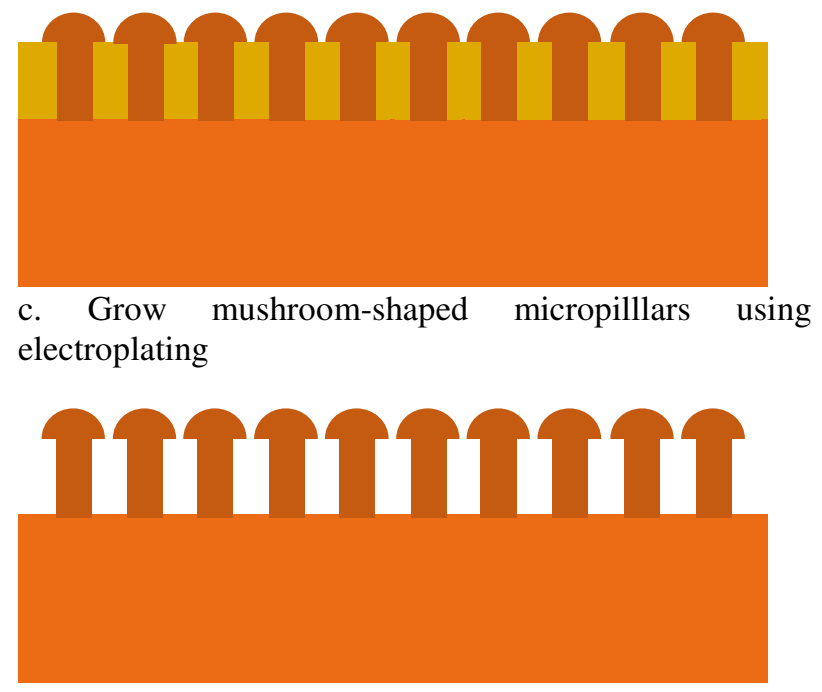

d. Remove the polyimide tape

Fig. 2 A process flow for micropillar array fabrication

Copper and copper-CNT composite were then electroplated on the polished copper specimen (Fig. 2c). Electroplating was performed in an electrochemical cell under continuous magnetic stirring in order to keep the particles in suspension. The composition of the electroplating bath was $65 \mathrm{~g} / \mathrm{lit} \mathrm{CuSO} 4.5 \mathrm{H} 2 \mathrm{O}, 70 \mathrm{~g} / \mathrm{lit} \mathrm{H} 2 \mathrm{SO} 4$ and 75 ppm Cl-. All chemicals were of analytical grade and the deionized water was of ultra-high purity. A copper plate (anode) of size of $5 \mathrm{~cm} \times 5 \mathrm{~cm}$ was positioned vertically parallel to the specimen (cathode). The gap between the anode and cathode was $3 \mathrm{~cm}$. The current density, bath temperature, and duration time were 7 $\mathrm{A} / \mathrm{dm}^{2}, 40{ }^{\circ} \mathrm{C}$, and 2 hours, respectively. During the electroplating process, the solution was stirred by a magnetic stirrer with a length of $2 \mathrm{~cm}$ at $600 \mathrm{rpm}$. Multi-walled carbon nanotubes (MWCNTs) with a diameter of less than $10 \mathrm{~nm}$ and a length of 1-2 $\mu \mathrm{m}$ were purchased from Sigma-Aldrich Corporation (St. Louis, MO). To prevent agglomeration of CNTs due to strong van der Waals forces between CNT particles, different amounts of CNT particles (1, 2, 3 and 4 $\mathrm{gr} / \mathrm{lit}$ ) were first added to a mixture of $20 \mathrm{ml}$ of water and $2 \mathrm{~g} / \mathrm{lit}$ Sodium dodecyl sulfate (SDS). SDS has been shown to be an effective anodic inhibitor for copper, especially at lower anodic overvoltage in an acidic solution [30]. The solution was then subjected to ultrasonic vibration for 2 hours at $21 \mathrm{kHz}$. After sonication, the CNT solution was added to the copper electroplating 
This is an author-created, un-copyedited version of an article published in Materials Research Express. IOP Publishing Ltd is not responsible for any errors or omissions in this version of the manuscript or any version derived from it. The Version of Record is available online at doi:10.1088/2053-1591/2/7/075501.

bath to prepare copper micropillars with different CNT volume fractions. The volume fraction of CNTs in the micropillars was determined using Clemex image analyzer software. After electroplating, the sample was cleaned in $200 \mathrm{~g} / \mathrm{lit} \mathrm{NaOH}$ solution to remove the polyimide adhesives (Fig. 2d), followed by deionized water for $1 \mathrm{~min}$. The diameter and height of the fabricated micropillars were approximately $500 \mu \mathrm{m}$ and $200 \mu \mathrm{m}$, respectively. These mushroomshaped micropillars provide a larger capillary pressure due to a smaller spacing between the mushroom heads on top of the pillars, while providing a higher liquid permeability due a larger spacing at the base of the pillars. These unique features can significantly increase the performance of mushroom-shaped micropillars as advanced wicking structures for applications in thermal management of electronics devices.

Phase characterization of the micropillars was investigated using X-ray diffraction (XRD). The surface morphologies and elemental analysis of the samples were investigated using a Nikon Eclipse H550s optical microscope. The specimen were polished with $1200 \mathrm{SiC}$ water proof paper and etched in $\mathrm{HNO}_{3}+\mathrm{H}_{2} \mathrm{O}_{2}+\mathrm{H}_{2} \mathrm{O}$ solution to reveal the microstructure of the copper and copperCNT micropillars. To examine the cross sections of the specimen, the samples were attached vertically to a support material using an epoxy adhesive. Corrosion resistance properties were examined using electrochemical impedance spectroscopy in $3.5 \mathrm{wt}$. \% $\mathrm{NaCl}$ solutions at room temperature $\left(25^{\circ} \mathrm{C}\right)$. For EIS measurement, a GAMRY Reference 3000 with a three-electrode setup was used. The specimen was used as a working electrode. The counter electrode was a platinum electrode and the reference electrode was a saturated calomel electrode (SCE). Before running the corrosion test, the specimens were cleaned with acetone and rinsed with deionized water. EIS measurements used an initial frequency of $0.05 \mathrm{~Hz}$, a final frequency $100 \mathrm{kHz}$, at a rate of 10 measurements per decade, with an $\mathrm{AC}$ current of $0.1 \mathrm{~A}$. The time delay before integration was $100 \mathrm{~s}$. The impedance spectra were obtained on each sample one hour after immersion and recorded in the form of Nyquist plots. An equivalent electrical circuit is the most common method for investigating EIS spectra. As shown in Fig. 3, the impedance of electrodesolution double layer is represented by a simple electrical circuit and it consists of a solution resistance $\left(R_{\mathrm{s}}\right)$ between the reference electrode and the working electrode, a corrosion resistance 
This is an author-created, un-copyedited version of an article published in Materials Research Express. IOP Publishing Ltd is not responsible for any errors or omissions in this version of the manuscript or any version derived from it. The Version of Record is available online at doi:10.1088/2053-1591/2/7/075501.

$\left(\mathrm{R}_{\mathrm{p}}\right)$, and a constant phase element (CPE). In this study, a constant phase element (CPE) was used in the model since the surface roughness of the electrode is dependent on the frequency. EIS data were fitted using Zview II software.

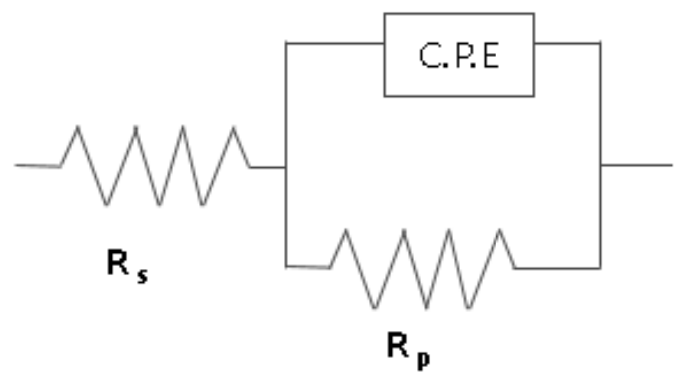

a)

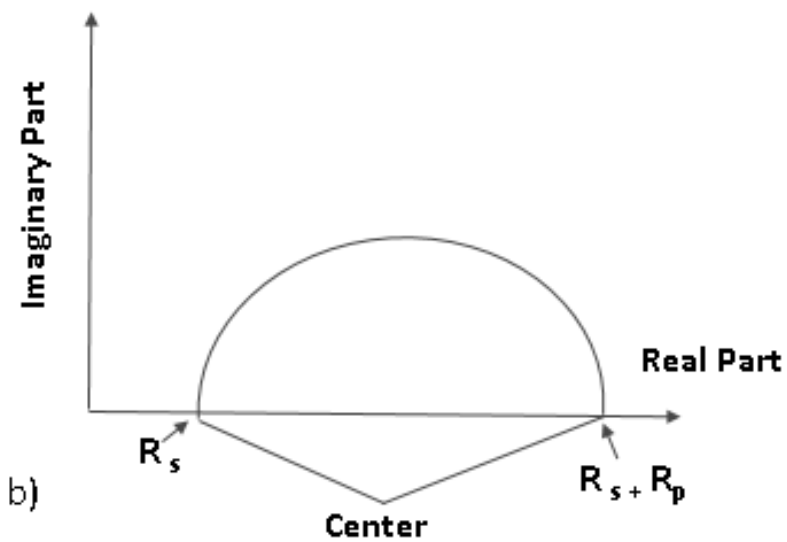

Fig. 3: (a) An equivalent electrical circuit for fitting the experimental impedance data, consisting of a constant phase element $(\mathrm{CPE})$, a solution resistance $\left(\mathrm{R}_{\mathrm{s}}\right)$, and a corrosion resistance $\left(\mathrm{R}_{\mathrm{p}}\right)$. (b) A corresponding Nyquist impedance plot.

\section{Results and discussion}

\subsection{Morphology and electrochemical parameters}

Representative images of fabricated copper micropillars are shown in Fig. 4. As seen there, mushroom-shaped structures were successfully fabricated. The gap between the mushroom heads on top of the pillars can be controlled by controlling the electroplating time. The side wall of the micropillars was observed to be smooth. Current density is a crucial factor in determining the optimal electroplating conditions for the fabrication of micropillars. For the bath composition used in this study, the optimum current density for the micropillars fabrication was found to be approximately $7 \mathrm{~A} / \mathrm{dm}^{2}$ at $40{ }^{\circ} \mathrm{C}$. A current density of higher than $7 \mathrm{~A} / \mathrm{dm}^{2}$ was found to produce non-uniform pillars and reduce the penetration of the copper electroplating solution into the micro holes due to the hydrogen reduction. Additionally, copper-CNT composite micropillars were successfully electrodeposited on a polished copper substrate. Various amounts of CNT particles (1, 2, 3 and $4 \mathrm{~g} / \mathrm{lit}$ ) were added to the solution. The maximum volume fraction of CNT 
This is an author-created, un-copyedited version of an article published in Materials Research Express. IOP Publishing Ltd is not responsible for any errors or omissions in this version of the manuscript or any version derived from it. The Version of Record is available online at doi:10.1088/2053-1591/2/7/075501.

in the copper-CNT micropillars was obtained at a current density of approximately $7 \mathrm{~A} / \mathrm{dm}^{2}$ or a CNT concentration of $3 \mathrm{~g} /$ lit in the solution. Optical microscopy images of a copper micropillar and a copper-CNT micropillar under optimum conditions are shown in Fig. 5. These images show significant differences between the average grain sizes of these two samples. Also, the CNT particles are homogeneously dispersed and the grain size is reduced in the copper-CNT micropillars.

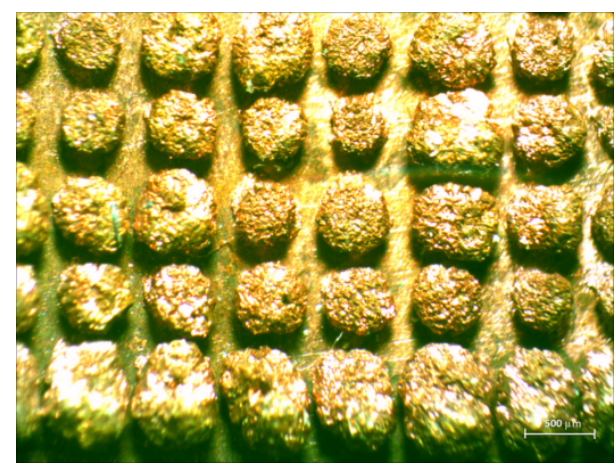

(a) top view of copper micropillars

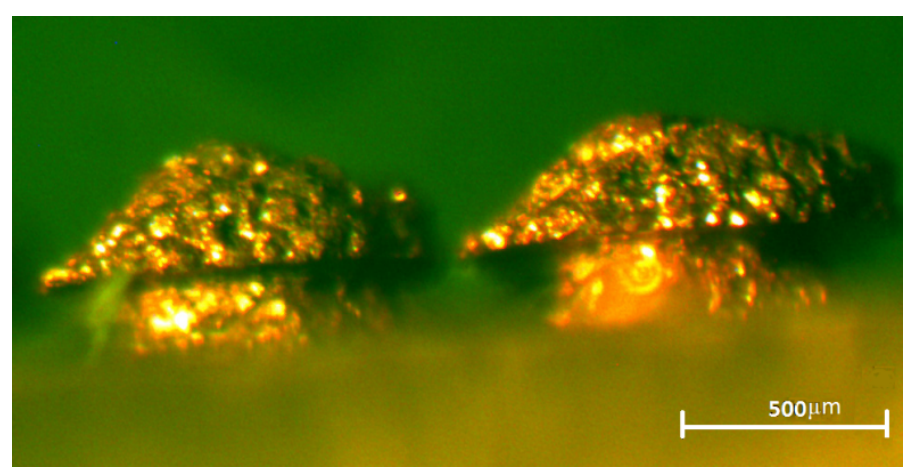

(b) side view of mushroom-shaped copper micropillars

Fig. 4 Optical micrographs of copper micropillars

The variation of volume fractions of CNT particles as functions of CNT concentration and current density are shown in Fig. 6. The deposition mechanism can be explained by the CelisRoos [14] model using the five-step process, described in the introduction section. The results show that the volume faction of CNT in the copper-CNT composite micropillars increases initially with increasing the current density or the CNT concentration in the solution. However, as the CNT concentration or current density is further increased, the volume faction of CNT in the composite micropillars decreases. These results indicate that there is an optimum current density and CNT concentration at which the maximum volume fraction of CNT in the composite layer is obtained. This behavior is similar to other composite coatings reported in the literature such as $\mathrm{Ni}-\mathrm{Al}_{2} \mathrm{O}_{3}[4,5]$, Ni graphite [6], Ni-WC [7, 8], Ni-SiC [9, 10], and $\mathrm{Ni}^{-\mathrm{SiO}_{2}}$ [11]. According to Celis-Roos model, $\mathrm{Cu}^{2+}$ ions are attracted to the negatively charged CNT particles (due to adsorption of SDS on CNT surface) and $\mathrm{Cu}^{2+}-\mathrm{CNT}$ complexes are formed. These $\mathrm{Cu}^{2+}$ CNT complexes are attracted by electrostatic forces. However, with increasing CNT 
concentration in the electroplating solution, the CNT content in the Helmholtz layer increases as well, resulting in a decrease in the $\mathrm{Cu}^{2+}$-CNT complex in Helmholtz layer. In addition, at higher CNT concentrations, agglomeration of CNT particles causes a reduction in the CNT particle deposition in the double layer. The results show that a higher current density increases the amount of CNTs in the composite layer. This phenomenon can be explained by the activation control mechanism. With increasing the current density, $\mathrm{Cu}^{2+}-\mathrm{CNT}$ complex and $\mathrm{Cu}^{2+}$ move faster to the double layer due to larger electrostatic forces. However, at higher current densities, $\mathrm{Cu}^{2+}$ move faster than $\mathrm{Cu}^{2+}$-CNT complex, resulting in a higher $\mathrm{Cu}^{2+}$ ions reduction on the cathode surface. Thus, the concentration of $\mathrm{Cu}^{2+}-\mathrm{CNT}$ decreases on the cathode surface. This step is controlled by $\mathrm{Cu}^{2+}$ diffusion. Furthermore, a higher current density causes more hydrogen reduction, which serves as a barrier for $\mathrm{Cu}^{2+}-\mathrm{CNT}$ complex on the cathode surface [14]. This behavior is consistent with our observations during electroplating of copper-CNT complex where more bubbles were observed at higher current densities. 
This is an author-created, un-copyedited version of an article published in Materials Research Express. IOP Publishing Ltd is not responsible for any errors or omissions in this version of the manuscript or any version derived from it. The Version of Record is available online at doi:10.1088/2053-1591/2/7/075501.
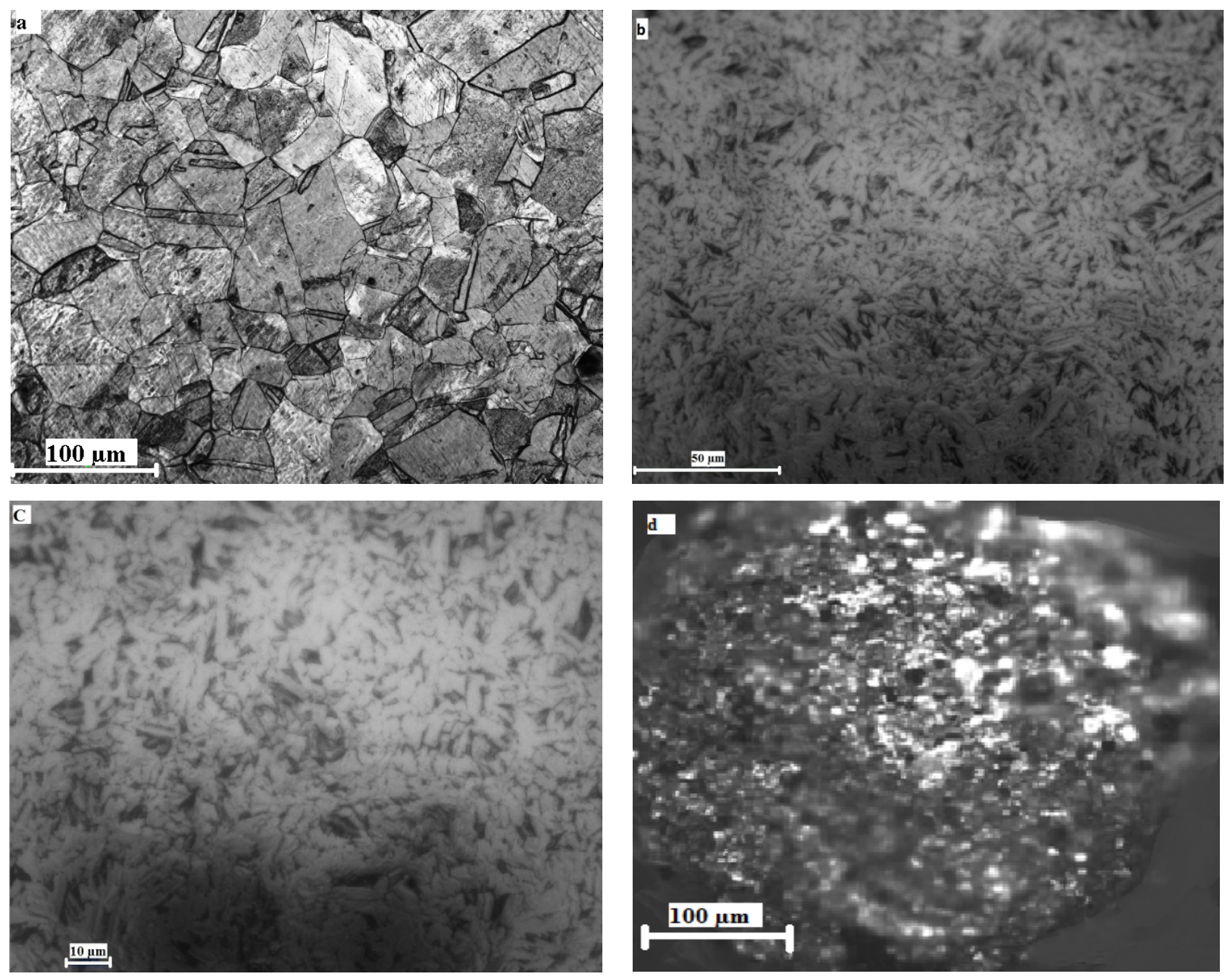

Fig. 5 Optical micrographs of a) a polished electroplated copper micropillar; b) and c) a polished copper-CNT micropillar (CNT content of $\left.3 \mathrm{~g} / \mathrm{lit}, \mathrm{i}_{\mathrm{d}}=7 \mathrm{~A} / \mathrm{dm}^{2}\right)$; d) top view of a copper-CNT micropillar 
This is an author-created, un-copyedited version of an article published in Materials Research Express. IOP Publishing Ltd is not responsible for any errors or omissions in this version of the manuscript or any version derived from it. The Version of Record is available online at doi:10.1088/2053-1591/2/7/075501.

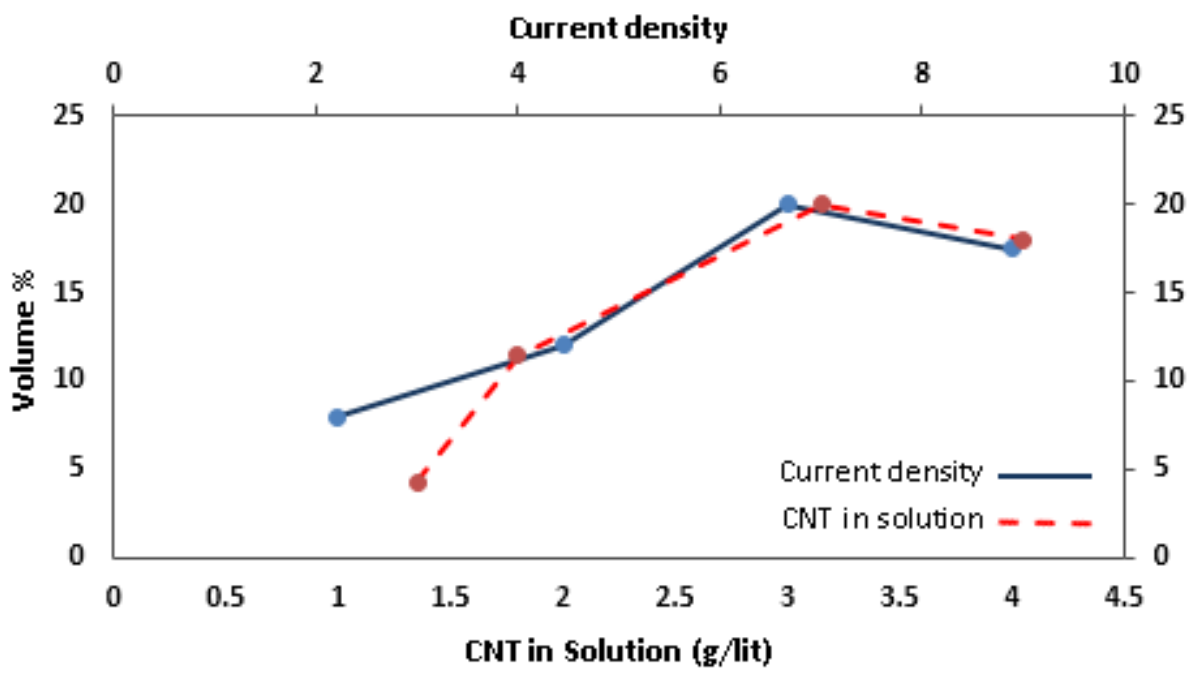

Fig. 6 Volume fraction of CNT in the copper-CNT composite micropillars as a function of CNT concentration in the solution at a constant current density of $7 \mathrm{~A} / \mathrm{dm}^{2}$ (red line); and as a function current density at a CNT concentration of $3 \mathrm{~g} / \mathrm{lit}$ in the solution (blue line)

\subsection{X-ray diffraction (XRD) analysis}

Figure 7 shows an XRD image of copper-CNT micropillars, indicating three different orientation peaks for copper and one peak for carbon. The deposition of CNT particles in copper matrix resulted in a decrease in the copper crystal size and an increase in the intensity of (200) crystal orientation in copper matrix. For the composite copper-CNT micropillars, the average grain sizes of the pillars were calculated from the Scherer equation given by:

where $\mathrm{B}$ is the line broadening at half the maximum intensity in radians, $\theta$ is the Bragg angle, $\mathrm{t}$ is the average size of the ordered (crystalline) domains, and $\square$ is the X-ray wavelength. In composite copper-CNT micropillars with $20 \mathrm{wt}$ \% CNT, the average size of the copper crystallite was calculated to be $23 \mathrm{~nm}$. The grain size of composite copper-CNT micropillars was smaller than the grain size of the copper matrix. This can be explained by the fact that when particles in the bath precipitate on the copper matrix, they prevent grain growth and provide more heterogeneous nucleation sites [31]. 
This is an author-created, un-copyedited version of an article published in Materials Research Express. IOP Publishing Ltd is not responsible for any errors or omissions in this version of the manuscript or any version derived from it. The Version of Record is available online at doi:10.1088/2053-1591/2/7/075501.

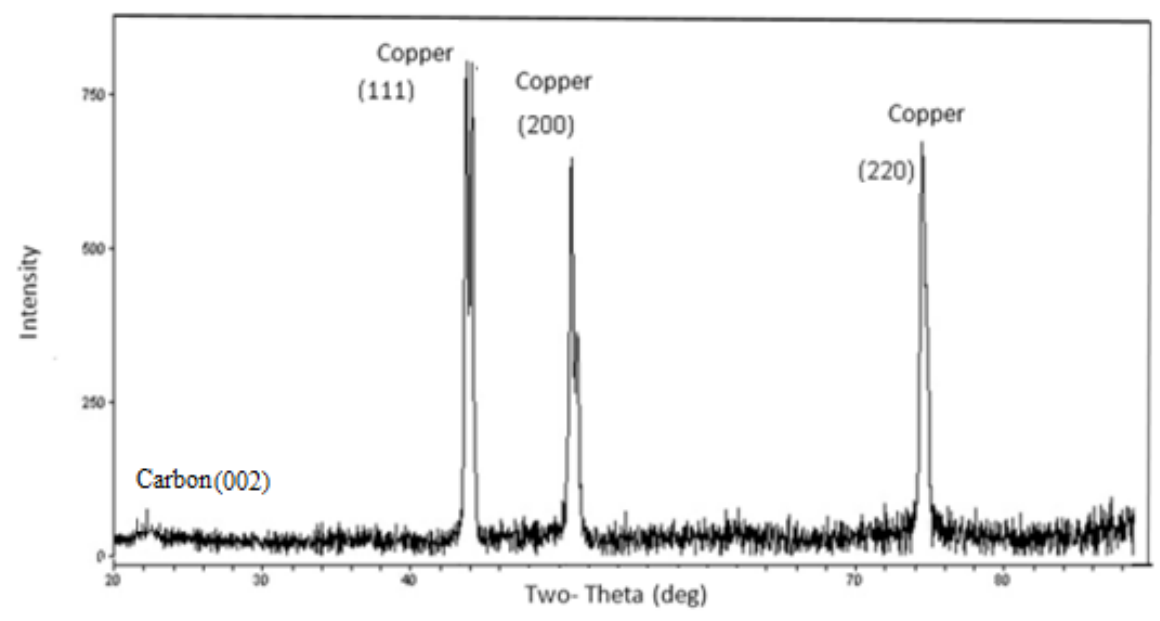

Fig. 7 An XRD image of copper-CNT micropillars

\subsection{Electrochemical impedance spectroscopy (EIS) studies}

To examine the corrosion behavior of each sample, impedance measurements were made for a copper substrate, electroplated copper micropillars, and copper-CNT composite micropillars. Each specimen was immersed into a $3.5 \% \mathrm{NaCl}$ solution and its open circuit potential was monitored until a stable value was reached as depicted in Fig. 8. Nyquist plots and Bode impedance curves are depicted in Figs. 9 and 10. The results indicate that the copper substrate, copper micropillars, and copper-CNT micropillars display similar semicircular curves at high frequencies as depicted by the Nyquist plots. Furthermore, the shape of the Nyquist plots show that the corrosion mechanism is similar in all cases. The results also indicate that the real impedance of the copper-CNT pillars is higher than those of a copper substrate and electroplated copper micropillars. This is due to a higher $\mathrm{R}_{\mathrm{p}}$ for copper-CNT micropillars at low frequencies as shown in Fig. 9. Table 1 summarizes the electrochemical impedance parameters obtained from the equivalent circuit for a copper substrate, copper micropillars, and copper-CNT micropillars. To obtain the impedance, the following equation can be used [32]:

$$
0<\beta \leq 1
$$


This is an author-created, un-copyedited version of an article published in Materials Research Express. IOP Publishing Ltd is not responsible for any errors or omissions in this version of the manuscript or any version derived from it. The Version of Record is available online at doi:10.1088/2053-1591/2/7/075501.

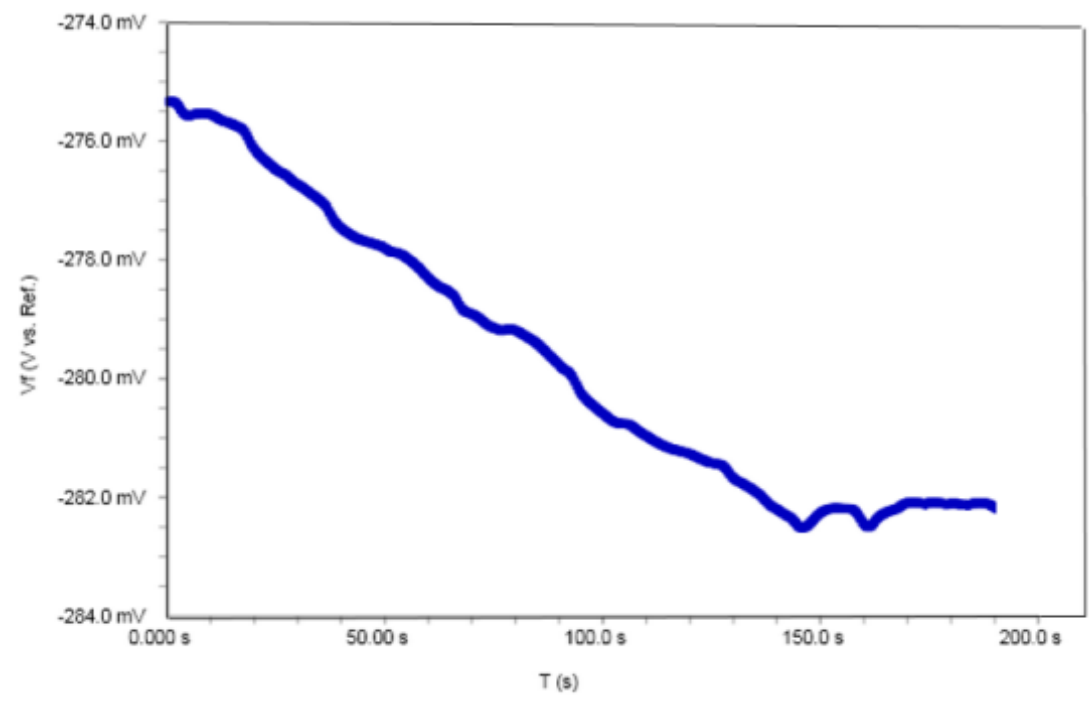

Fig. 8 An open circuit potential for a copper substrate

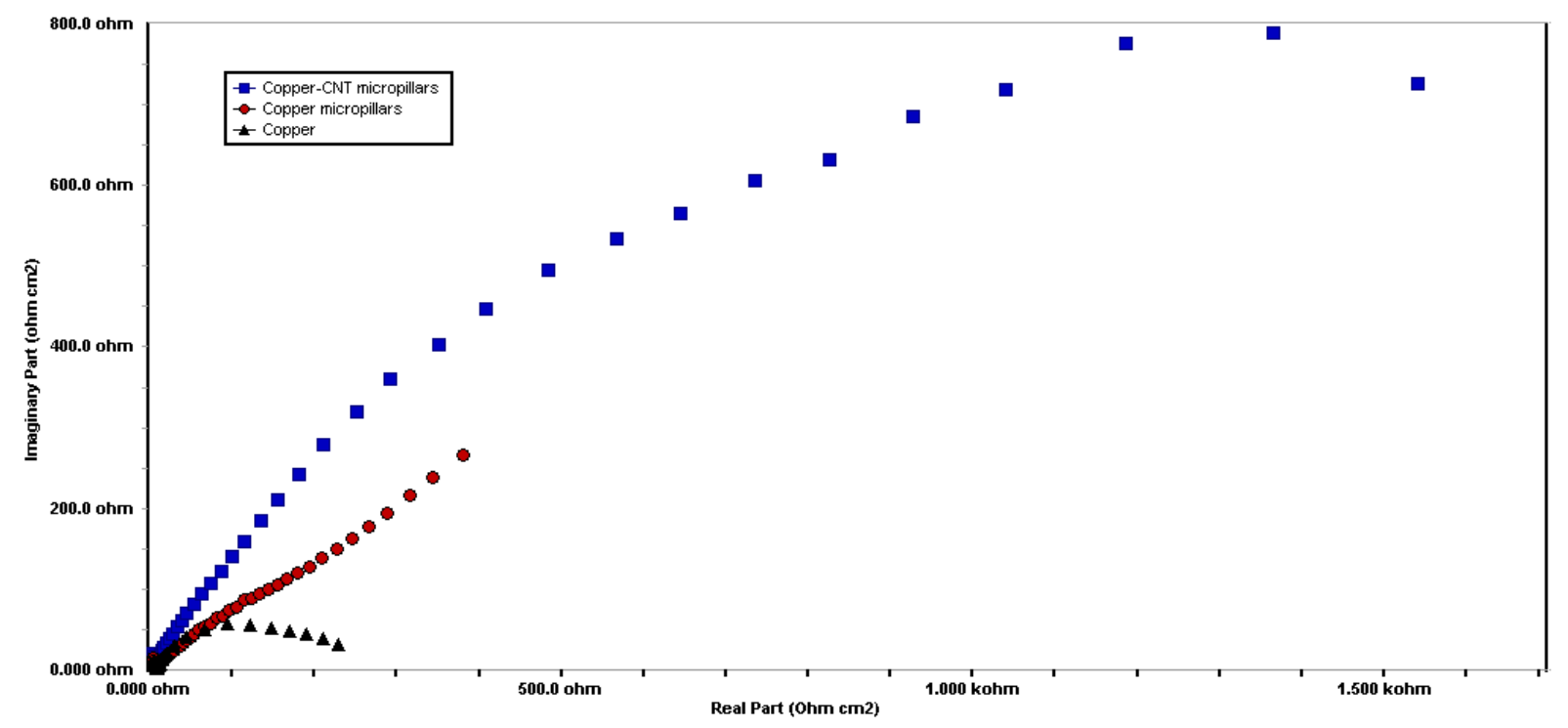

Fig. 9 Nyquist plots for a copper substrate, copper micropillars, and copper-CNT micropillars at a CNT concentration of $3 \mathrm{~g} / \mathrm{lit}$ and a current density of $7 \mathrm{~A} / \mathrm{dm}^{2}$ 
This is an author-created, un-copyedited version of an article published in Materials Research Express. IOP Publishing Ltd is not responsible for any errors or omissions in this version of the manuscript or any version derived from it. The Version of Record is available online at doi:10.1088/2053-1591/2/7/075501.

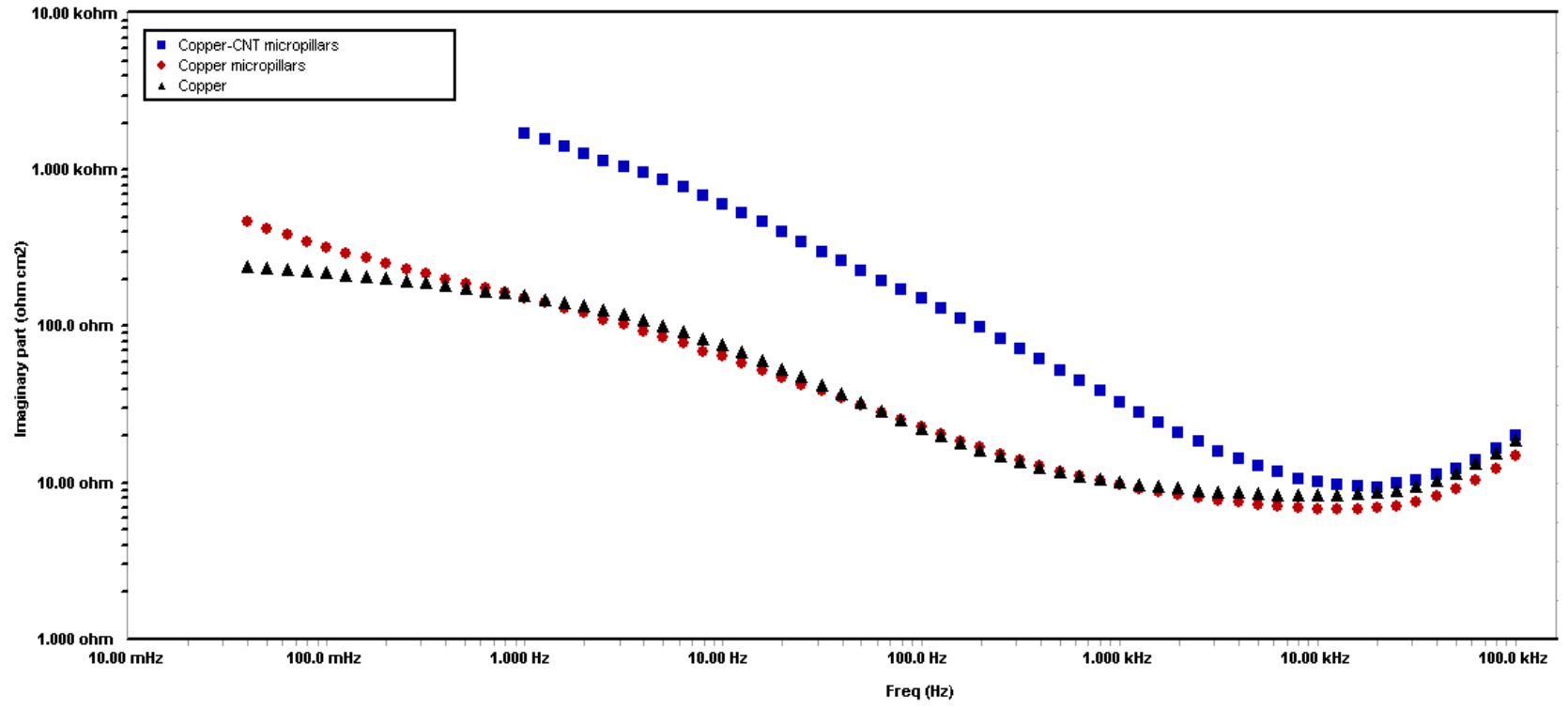

Fig. 10 Bode plots for a copper substrate, copper micropillars, and copper-CNT micropillars a CNT concentration of $3 \mathrm{~g} /$ lit and a current density of $7 \mathrm{~A} / \mathrm{dm}^{2}$

The diameter of semicircles on the Nyquist plots is related to the corrosion resistance of copper micropillars and copper-CNT micropillars. A higher value of corrosion resistance is obtained for copper-CNT micropillars and copper micropillars. It has been reported that high values of $\mathrm{R}_{\mathrm{p}}$ and low values of CPE represent a better corrosion resistance $[33,34]$. As shown in Table 1, the Rp value for the copper-CNT micropillars is approximately 6 and 13 times higher than those of copper micropillars and copper substrate, respectively. Also, it was observed that the CPE-T value for copper-CNT micropillar is less than copper micropillars, indicating that copper micropillars are more porous compared to those of copper-CNT micropillars. The improvement in the corrosion resistance of the electroplated copper micropillars compared to the bare copper substrate is due to a decrease in the hydrogen reduction caused by the difference in the anodic and cathodic surface areas. Copper micropillars act as a cathodic area and the substrate acts as an anodic area. However, the cathodic area is much smaller than the anodic area, resulting in a decrease in the hydrogen reduction. A better corrosion resistance of copper-CNT composite micropillars compared to copper micropillars can be attributed to several factors, including a low chemical reactivity of CNTs [33] and a less active metallic area on the surface of micropillars 
This is an author-created, un-copyedited version of an article published in Materials Research Express. IOP Publishing Ltd is not responsible for any errors or omissions in this version of the manuscript or any version derived from it. The Version of Record is available online at doi:10.1088/2053-1591/2/7/075501.

due to the presence of CNTs. In addition, CNTs can enhance the corrosion resistance by filling microholes in the micropillar structures $[35,36]$. The addition of small quantities of CNT to the copper matrix causes an increase in the corrosion resistance. However, when the CNT amount exceeds the optimum value, the density of micro holes, agglomeration of CNTs, and coherency can be increased. As a result, the corrosion resistance of copper-CNT composite is decreased. Also, agglomeration of CNT on the copper surface can accelerate a local corrosion due to a positive potential $[37,38]$.

Table 1 Electrochemical parameters for various samples obtained from EIS data

\begin{tabular}{llll}
\hline Sample & Rs $\left(\mathbf{\Omega} \mathbf{c m}^{2}\right)$ & $\mathbf{R p}\left(\mathbf{\Omega} \mathbf{c m}^{2}\right)$ & $\mathbf{C P E}-\mathbf{T}\left(\mathbf{F ~ \mathbf { c m } ^ { 2 }}\right)$ \\
\hline Copper substrate & 7.6 & 200 & 0.0018 \\
Copper micropillars & 7.46 & 440 & 0.0028 \\
Copper-CNT micropillars* & 8.044 & 2550 & 0.0001 \\
\hline
\end{tabular}

*The results are obtained at a CNT concentration of $3 \mathrm{~g} /$ lit and a current density of $7 \mathrm{~A} / \mathrm{dm}^{2}$

\section{Conclusions}

In this study, copper micropillars and copper-CNT composite micropillars were successfully grown on a copper substrate using electroplating and Xurography method for applications in capillary-driven two-phase cooling systems such as passive heat pipes and vapor chambers. The results indicated that there was an optimum current density and a CNT concentration at which the maximum volume fraction of copper-CNT composite micropillars was obtained. CNT particles had a favorable effect on the composite grain size. The electrochemical test results showed that the corrosion resistance of copper-CNT composite micropillars was significantly higher than those of a planar copper substrate and copper micropillars. The enhancement was approximately 6 and 13 times higher than those of copper micropillars and copper substrate, respectively. The improvement in the corrosion resistance of copper-CNT composite micropillars is believed to be due to high chemical stability of CNTs and a decrease in the active metallic nanostructures on the surface of micropillars due to the presence of CNTs. 
This is an author-created, un-copyedited version of an article published in Materials Research Express. IOP Publishing Ltd is not responsible for any errors or omissions in this version of the manuscript or any version derived from it. The Version of Record is available online at doi:10.1088/2053-1591/2/7/075501.

\section{References}

[1] Buelens C, Celis JP, Roos JR, Electrochemical aspects of the co deposition of gold and copper with inertparticles. J Appl Electrochem 1983;13:541-548.

[2] Iwakura C, Furukowa N, Tanaka M, Nakamatsu S. Electrochemical properties of Ni/ (Ni + $\mathrm{RuO} 2$ ) active cathodes for hydrogen evolution in chlor-alkali electrolysis. Electrochim acta 1995; 40: 977-982.

[3] Belenkij MA, Ivanov AF. Elektroosazdenie Metallitcheskih Pokritij. Metallurgiya. Moscow, 1985.

[4] P. M. Vereecken, I. Shao and P. C. Searson, Particle Codeposition in Nanocomposite Films, J. Electrochem. Soc. 2000 volume 147, issue 7, 2572-2575. doi: 10.1149/1.1393570.

[5] Donga YS, Lina PH, Wang HX. Electroplating preparation of $\mathrm{Ni}-\mathrm{Al}_{2} \mathrm{O}_{3}$ graded composite coatings using a rotating cathode. Surf Coat Technol 2006; 200:3633-3636.

[6] Bercot P, Pe`na-Mu`noz E, Pagetti J. Electrolytic composite Ni-PTFE coatings and adaptation of Guglielmi's model for the phenomena of incorporation. Surf Coat Technol 2002; 157:282-9.

[7] Surender M, Basu B, Balaubramaniam R. Wear characterization of electro- deposited Ni-WC composite coatings. Tribol Int 2004; 37:743-9.

[8] Stroumbouli M, Gyftou P, Pavlatou EA, Spyrellis N. Codeposition of ultrafine WC particles in Nimatrix composite electro coatings. Surf Coat Technol 2005; 195:325-32.

[9] Gyftou P, Pavlatou EA, Spyrellis N. Effect of pulse electro deposition parameters on the properties of Ni/nano-SiC composites. Appl Surf Sci 2008; 254:5910-5916. 
This is an author-created, un-copyedited version of an article published in Materials Research Express. IOP Publishing Ltd is not responsible for any errors or omissions in this version of the manuscript or any version derived from it. The Version of Record is available online at doi:10.1088/2053-1591/2/7/075501.

[10] Cheng YT, Yu L, Xu SZ, Zi QZ. Nickel co-deposition with SiC particles at initial stage. Metal Soci China 2008; 18:1128-1133.

[11] Yan L, Sirong YU, Jindan L, Zhiwu H, Dongsheng Y. Microstructure and wear resistance of electrodeposited $\mathrm{Ni}_{-} \mathrm{SiO}_{2}$ nano-composite coatings on AZ91HP magnesium alloy substrate. Nonferrous Metal Soci China 2011; 21:483-488.

[12] Pompei E, Magagnin L, Lecis N, Cavallotti PL. Electro deposition of nickel-BN composite coatings. Electchim Acta 2009; 54:2571-4.

[13] Chen XH, Cheng FQ, Li SL, Zhou LP, Li DY. Electro deposited nickel composites containing carbon nanotubes. Surf Coat Technol 2002;155:274-278.

[14] J. P. Celis, J. R. Roos and C. Buelens, A Mathematical Model for the Electrolytic Codeposition of Particles with a Metallic Matrix, doi: 10.1149/1.2100680, J. Electrochem. Soc. 1987 volume 134, issue 6, 1402-1408.

[15] Zhiwen X, Zhuangzhu L, Qin Y, Tian C, Sheng T, Yunjiao W, Yimin L. Improving anti wear and anti-corrosion properties of AM60 magnesium alloy by ion implantation and Al/AlN/CrAlN/CrN/MoS2 gradient duplex coating. Vacuum 2014; 101:171-176.

[16] Low CTJ, Wills RGA, Walsh FC. Electro deposition of composite coating containing nano particles in a metal deposit. Surf Coat Technol 2006; 201:371-383.

[17] Ghanbari S, Mahboubi F. Corrosion resistance of electrodeposited Ni-Al composite coatings on the aluminum substrate. Mater Des 2011;32:1859-1864.

[18] Lampke T, Wielage B, Dietrich D, Leopold A. Details of crystalline growth in co- deposited electro plated nickel films with hard nano particles. Appl Sur Sci 2006;253:2399-2408.

[19] B.M. Praveen, T.V. Venkatesha. Electrodeposition and properties of Zn-Ni-CNT composite coatings. J Alloys Compd 2009;482:53-57.

[20] Sun Y, Sun J, Liu M, Chen Q. Mechanical strength of carbon nanotube-nickel Nano composites. Nanotechnology 2007;18:505-704. 
This is an author-created, un-copyedited version of an article published in Materials Research Express. IOP Publishing Ltd is not responsible for any errors or omissions in this version of the manuscript or any version derived from it. The Version of Record is available online at doi:10.1088/2053-1591/2/7/075501.

[21] Shi L, Sun CF, Gao F. Electrodeposition and characterization of Ni-Co-carbon nanotubes composite coatings. Surf Coat Technol 2006;200:48-70.

[22] Chen XH, Chen CS, Xiao HN. Corrosion behavior of carbon nanotubes-Ni composite coating. Surf Coat Technol 2005; 191:351-356.

[23] Min Deng, Guifu Ding, Yan Wang, Yuchao Wang, Hong Wang and Shi Fu, MEMS-based carbon nanotube and carbon nanofiber Cu micro special electric contact, 2009 J. Micromech. Microeng. 19065001 doi:10.1088/0960-1317/19/6/065001

[24] S. Khabazian, Sohrab S. Successful Incorporation of multi-walled carbon nanotubes in nickel electrodeposited coating by electrophoresis . Appl Sur Sci 2011;257:9366-9370.

[25] Jeona YS, Byunb JY, Oh TS. Electrodeposition and mechanical properties of Ni-carbon nanotube nanocomposite coating. J Phys Chem Solids 2008; 69:1391-1394.

[26] Guo C, Zuo Y, Zhao X, Zhao J, Xiong J. Effects of surfactants on electrodeposition of nickel-carbon nanotubes composite coatings. Surf Coat Technol 2008;20:3385-3390.

[27] BarCohen A, Wang P, Rahim E. Thermal Management of High Heat Flux Nanoelectronic Chips. Micro gravity Sci Technol 2007;19: 48-52.

[28] Swanson TD, Birur GC. NASA thermal control technologies for robotic spacecraft. Appl Therm Eng 2003; 23:1055-1065.

[29] Bartholomeusz, D.A.; Boutte, R.W.; Andrade, J.D., "Xurography: rapid prototyping of microstructures using a cutting plotter," Microelectromechanical Systems, Journal of , vol.14, no.6, pp.1364,1374, Dec. 2005

[30] Fuchs-Gode R, Dolecek V.A. An effect of sodium dodecylsulfate on the corrosion of copper in sulphuric acid media. Colloids and surface A: Physicochem 2004; 244:73.

[31] McCormack AG, Pomeroy MJ, Cunnane VJ. Microstructural Development Surface characterization of electrodeposited nickel/yttria composite coatings. J Electrochem Soc 2003; 150:356-361. 
This is an author-created, un-copyedited version of an article published in Materials Research Express. IOP Publishing Ltd is not responsible for any errors or omissions in this version of the manuscript or any version derived from it. The Version of Record is available online at doi:10.1088/2053-1591/2/7/075501.

[32] Lemoine L, Wenger F, Galland J. Special Technical Publication. vol 1065, American Society for Testing and Materials, Philadelphia, USA. 1990.

[33] Kamachi Mudali U, Kaul R, Ningshen S, Ganesh P, Nath A.K, Khatak H.S, Baldev R. Influence of laser surface alloying whit chromium and nickel on corrosion resistance of type 304L stainless steel materials. Mater Sci Tech. 2006; 22:1185.

[34] Bojinov M, Betova I, Fabricius G, Laitinen T, Raicheff R, Saario T. The stability of the passive state of iron-chromium alloys in sulphuric acid solution. Corros Sci 1999; 41:1557.

[35] Krishnaveni K, Narayanan S, Seshadri SK. Corrosion resistance of electrodeposited Ni-B and $\mathrm{Ni}-\mathrm{B}-\mathrm{Si}_{3} \mathrm{~N}_{4}$ composite coatings. J Alloys Compd 2009;480:765-770.

[36] Li Q, Yang X, Zhang L, Wang J, Bo C. Corrosion resistance and mechanical properties of pulse electrodeposited Ni-TiO2 composite coating for sintered NdFeB magnet. J Alloys Compd 2009;482:339-344.

[37] Mindivan H, Efe A, Hadi Kosatepe A, Sabri Kayali E. Fabrication and characterization of carbon nanotube reinforced magnesium matrix composites. Appl Surf Sci 2014; 318: 234-243.

[38] Zarebidaki A, Allahkaram S. Effect of surfactant on the fabrication and characterization of Ni-P-CNT composite coatings. J Alloys Compd 2011; 509: 836-1840. 